\title{
Fabrication and Adsorption Behavior of Magnesium Silicate Hydrate Nanoparticles towards Methylene Blue
}

\author{
Renyao Huang ${ }^{1}$, Li He ${ }^{1}$, Tao Zhang ${ }^{2}$, Dianqing Li ${ }^{1}$, Pinggui Tang ${ }^{1}$, Yingying Zhao ${ }^{1, *}$ \\ and Yongjun Feng $1, *$ (i) \\ 1 State Key Laboratory of Chemical Resource Engineering, Beijing Engineering Center for Hierarchical \\ Catalysts, Beijing University of Chemical Technology, Beijing 100029, China; \\ huangrenyao203@163.com (R.H.); 13260178198@163.com (L.H.); lidq@mail.buct.edu.cn (D.L.); \\ tangpg@mail.buct.edu.cn (P.T.) \\ 2 Beijing Center for Physical \& Chemical Analysis, Beijing 100089, China; zhtao08@163.com \\ * Correspondence: zhaoyy@mail.buct.edu.cn (Y.Z.); yjfeng@mail.buct.edu.cn (Y.F.); \\ Tel.: +86-10-64425385(Y.Z. \& Y.F.)
}

Received: 13 March 2018; Accepted: 20 April 2018; Published: 24 April 2018

\begin{abstract}
Magnesium silicate as a high-performance adsorption material has attracted increasing attention for the removal of organic dye pollution. Here, we prepared a series of magnesium silicate hydrates (MSH) in a hydrothermal route, and carefully investigated the corresponding adsorption behavior towards methylene blue (MB) as well as the effect of surface charge on adsorption capacity. The results show that surface charge plays a key role in the adsorption performance of $\mathrm{MSH}$ for $\mathrm{MB}$, a negative surface charge density follows the increase of $\mathrm{Si} / \mathrm{Mg}$ feeding ratio from 1.00 to 1.75, and furthermore the higher negative charge favors the improvement of the adsorption capacity. Among four investigated samples ( $\mathrm{MSH}=1.00,1.25,1.50$, and 1.75), MSH-1.75 has the highest negative surface charge and shows the largest adsorption capacity for MB. For example, the equilibrium adsorption quantity is $307 \mathrm{mg} \cdot \mathrm{g}^{-1}$ for MSH-1.75, which is $35 \%$ higher than that of $227 \mathrm{mg} \cdot \mathrm{g}^{-1}$ for MSH-1.00. Besides, for MSH-1.75, the as-prepared sample with negative charge exhibits ca. $36 \%$ higher adsorption quantity compared to the sample at the zero point of charge $\left(\mathrm{pH}_{\mathrm{ZPC}}\right)$. Furthermore, magnesium silicate hydrate material with $\mathrm{Si} / \mathrm{Mg}$ feeding ratio $=1.75$ demonstrates the promising removal efficiency of beyond $98 \%$ for methylene blue in $10 \mathrm{~min}$, and the maximum adsorption capacity of $374 \mathrm{mg} \cdot \mathrm{g}^{-1}$ calculated from the Langmuir isotherm model.
\end{abstract}

Keywords: magnesium silicate; adsorption behavior; methylene blue; surface charge

\section{Introduction}

Various synthetic dyes have been developed and have played an important role in modern life. During the process of production and application, however, ca. $10 \%$ of synthetic dyes are inevitably released to the environment as the main components in effluent wastewaters [1], which have seriously negative influences on the chemical oxygen demand, biological oxygen demand, $\mathrm{pH}$ value and translucency to an unacceptable level, and furthermore are threatening the environment and human health [2].

The trend in water and wastewater treatment is continuously moving towards more sustainable materials and technologies [3]. Recently, magnesium silicate as a high-performance and sustainability adsorption material has attracted increasing interest to remove heavy metal ions and various kinds of dyes [4,5]. However, most special attentions has been paid to the enhancement of adsorption capacity by 
increasing surface area and optimizing pore size, such as mesoporous [6], hierarchical [7], nanosized [8], sandwich-like [9], nanotubes [10], and yolk-shell magnesium silicate [11]. Besides the pore structure, the surface properties also play crucial roles in enhancing the adsorption capacity [12-16]. For example, Ferrero [17] considered that the adsorption mechanism of magnesium silicate was concerned with both of the electrostatic attraction and the ion-exchange for methylene blue. To date, few reports have been published on the detailed relationship between surface charge and adsorption behavior on magnesium silicate material.

In this work, we fabricated a series of magnesium silicate hydrate (MSH) adsorbents with different surface charge density by adjusting the $\mathrm{Si} / \mathrm{Mg}$ feeding ratio in a hydrothermal route, and carefully investigated the corresponding adsorption behavior for methylene blue as well as the relationship between surface charge density and adsorption capacity.

\section{Experimental}

\subsection{Materials}

The magnesium nitrate hexahydrate $\left(\mathrm{Mg}\left(\mathrm{NO}_{3}\right)_{2} \cdot 6 \mathrm{H}_{2} \mathrm{O}\right)$, sodium silicate nonahydrate $\left(\mathrm{Na}_{2} \mathrm{SiO}_{3} \cdot 9 \mathrm{H}_{2} \mathrm{O}\right)$, hydrochloric acid $(\mathrm{HCl}, 36.5 \mathrm{wt} \%)$, sodium chloride $(\mathrm{NaCl})$ and methylene blue $(\mathrm{MB})$ were all analytical grade and directly used as received from ALADDIN (Shanghai, China). The water used in this work was deionized water.

\subsection{Preparation of Magnesium Silicate Hydrate}

Four magnesium silicate samples with different surface charge densities were individually prepared in a hydrothermal route by adjusting the $\mathrm{Si} / \mathrm{Mg}$ feeding ratio. As for the sample with $\mathrm{Si} / \mathrm{Mg}$ ratio = 1.75, typically, $10.3 \mathrm{~g}(40 \mathrm{mmol}) \mathrm{Mg}\left(\mathrm{NO}_{3}\right)_{2} \cdot 6 \mathrm{H}_{2} \mathrm{O}$ and $17.1 \mathrm{~g}$ (70 mmol) $\mathrm{Na}_{2} \mathrm{SiO}_{3} \cdot 9 \mathrm{H}_{2} \mathrm{O}$ were separately dissolved in $200 \mathrm{~mL}$ of deionized water at $25^{\circ} \mathrm{C}$ to produce $0.2 \mathrm{~mol} \cdot \mathrm{L}^{-1} \mathrm{Mg}\left(\mathrm{NO}_{3}\right)_{2}$ solution and $0.35 \mathrm{~mol} \cdot \mathrm{L}^{-1} \mathrm{Na}_{2} \mathrm{SiO}_{3}$ solution. Both of two solutions were mixed under vigorous stirring for $3 \mathrm{~min}$. Subsequently, the resulting white slurry was transferred into an autoclave $(1 \mathrm{~L})$ and then kept at $190{ }^{\circ} \mathrm{C}$ for $12 \mathrm{~h}$ at the stirring speed of $300 \mathrm{rpm}$. Finally, the sample was collected after being washed by water, centrifuged, and dried at $60{ }^{\circ} \mathrm{C}$ for $12 \mathrm{~h}$. Another three samples were synthesized with the similar procedure and same amount of $\mathrm{Mg}\left(\mathrm{NO}_{3}\right)_{2} \cdot 6 \mathrm{H}_{2} \mathrm{O}$ but different $\mathrm{Si} / \mathrm{Mg}$ feeding ratios. Here, four samples were individually obtained and named as: $\mathrm{MSH}-1.00$ for $\mathrm{Si} / \mathrm{Mg}$ ratio = 1.00, $\mathrm{MSH}-1.25$ for $\mathrm{Si} / \mathrm{Mg}$ ratio = 1.25, $\mathrm{MSH}-1.50$ for $\mathrm{Si} / \mathrm{Mg}$ ratio = 1.50, and $\mathrm{MSH}-1.75$ for $\mathrm{Si} / \mathrm{Mg}$ ratio = 1.75.

\subsection{Characterization}

Crystal structure was determined by X-ray Diffraction (XRD) on a Rigaku UItima III X-ray powder diffractometer $(\mathrm{Cu} \mathrm{K} \alpha$ radiation, $\lambda=0.15406 \mathrm{~nm})$ in the range of $3^{\circ} \sim 70^{\circ} / 2 \theta$ with $10^{\circ} \mathrm{min}^{-1}$ (Tokyo, Japan). Particle size and size distribution were examined by Malvern Mastersizer 2000-Hydro 2000MU particle size analyzer (Malvern, UK) by dispersing the powder in water. Elemental analysis was performed using a Shimadzu ICPS-75000 (Kyoto, Japan) inductively coupled plasma atomic emission spectrometer (ICP-AES). Morphologies were recorded with a Hitachi S-4700 scanning electron microscope (SEM) (Eindhoven, The Netherlands) at $30 \mathrm{kV}$ and a JEOL JEM-2100F transmission electron microscope (TEM) (Tokyo, Japan). Elemental distribution was tested by a EDAX-GENESIS 60 energy-dispersive X-ray spectroscopy (EDX) (Mahwah, NJ, USA) coupled with SEM. Specific surface area and pore property were analyzed by low-temperature $\mathrm{N}_{2}$ adsorption-desorption method on Micromeritics ASAP 2390 (Norcross, GA, USA) volumetric adsorption analyzer. Considering the wide range of pore sizes from $0.5 \sim 200 \mathrm{~nm}$, the density functional theory (DFT) was used to calculate pore size distributions from adsorption isotherms based on given intermolecular fluid-fluid and fluid-solid potentials [18]. The $\mathrm{pH}$ value was measured by Mettler Toledo FE20 pH meter (Zurich, Switzerland) with LE438 combination electrodes with a resolution of 0.01 . Fourier transform infrared spectroscopy 
(FT-IR) spectra were collected on Bruker Vector 22 infrared spectrophotometer (Karlsruhe, Germany) in the wavenumber range of $400 \sim 4000 \mathrm{~cm}^{-1}$.

\subsection{Surface Charge Studies}

The surface charge of the samples was estimated according to the method of potentiometric titration [19]. To further investigate the quantitative change of adsorption capacity caused by surface charge, $32.5 \mathrm{mg}$ of MSH-1.75 was dispersed in a $100 \mathrm{~mL}$ flask containing $40 \mathrm{~mL}$ deionized water with a preset $\mathrm{pH}$ value adjusted by dilute $\mathrm{HCl}$ and the same ionic strength by adding $\mathrm{NaCl}$, respectively. Subsequently, nine flasks per $\mathrm{pH}$ value were sealed using plastic wrap, put in the thermostatic shaker, and shaken for $12 \mathrm{~h}$ at $25^{\circ} \mathrm{C}$ and $160 \mathrm{rpm}$, and the final $\mathrm{pH}$ values of the suspension were recorded. Then $10 \mathrm{~mL}, 1000 \mathrm{mg} \cdot \mathrm{L}^{-1} \mathrm{MB}$ solution was individually added into these flasks to produce a suspension containing $200 \mathrm{mg} \cdot \mathrm{L}^{-1} \mathrm{MB}$. These flasks were sealed using plastic wrap, put in the thermostatic shaker, and shaken for $0 \sim 120 \mathrm{~min}$ at $25^{\circ} \mathrm{C}(160 \mathrm{rpm})$. After a certain time, the suspension was separated by centrifugation ( $3700 \mathrm{rpm}, 5 \mathrm{~min}$ ), and the rest concentration of $\mathrm{MB}$ after adsorption was estimated by a UV/Vis spectrophotometer at $\lambda=664 \mathrm{~nm}$ [20]. The adsorption quantity $q_{t}$ of the sample at a certain time $t$ was calculated using the following equation [21]:

$$
q_{t}=\frac{\left(C_{0}-C_{t}\right) \times V}{m}
$$

where $q_{t}\left(\mathrm{mg} \cdot \mathrm{g}^{-1}\right)$ is the adsorption quantity of the sample for $\mathrm{MB}$ at the contact time $t(\mathrm{~min})$, $C_{0}\left(\mathrm{mg} \cdot \mathrm{L}^{-1}\right)$ is the initial concentrations of $\mathrm{MB}, C_{t}\left(\mathrm{mg} \cdot \mathrm{L}^{-1}\right)$ is the rest concentration of $\mathrm{MB}$ at the contact time $t(\mathrm{~min}), V(\mathrm{~L})$ and $m(\mathrm{~g})$ are the volume of $\mathrm{MB}$ solution and the mass of adsorbent sample, respectively.

\subsection{Adsorption Experiments}

The adsorption kinetic experiments were carried out in $100 \mathrm{~mL}$ flasks with the dispersion of $32.5 \mathrm{mg}$ of the prepared samples in $50 \mathrm{~mL}$ of $200 \mathrm{mg} \cdot \mathrm{L}^{-1} \mathrm{MB}$ solution. Subsequently, these flasks were sealed using plastic wrap, put in the thermostatic shaker, and shaken for $0 \sim 120 \mathrm{~min}$ at $25^{\circ} \mathrm{C}(160 \mathrm{rpm})$. Also, the adsorption isotherm experiments were performed in $100 \mathrm{~mL}$ flasks where $32.5 \mathrm{mg}$ of the sample was dispersed in $50 \mathrm{~mL}, 0 \sim 300 \mathrm{mg} \cdot \mathrm{L}^{-1} \mathrm{MB}$ solution for $120 \mathrm{~min}$. The concentration of MB and the adsorption quantities were determined using a UV/Vis spectrophotometer at $\lambda=664 \mathrm{~nm}$ and calculated following Equation (1). To estimate the regeneration properties, the MSH-1.75 sample after adsorption of $\mathrm{MB}$ was collected after being centrifugated, dried at $60^{\circ} \mathrm{C}$, and calcined at $600{ }^{\circ} \mathrm{C}$ for $4 \mathrm{~h}$ with a rate of $5{ }^{\circ} \mathrm{C} / \mathrm{min}$ in air [22], then the same adsorption isotherm experiments were repeated by dispersing $32.5 \mathrm{mg}$ of the regenerated samples in $50 \mathrm{~mL}$ of $100 \mathrm{mg} \cdot \mathrm{L}^{-1} \mathrm{MB}$ solution at $25^{\circ} \mathrm{C}$ for $120 \mathrm{~min}$.

All these experiments were carried out three times, and the average values were used to prepare the graphs in this work.

\section{Results and Discussion}

\subsection{Characterization}

Figure 1 shows the powder XRD patterns of four prepared MSH samples, which are very similar to those reported in the literature with three major broad peaks occurred at $2 \theta=20^{\circ} \sim 30^{\circ}, 35^{\circ}$ and $60^{\circ}$ for magnesium silicate hydrate (MSH) [23]. The low XRD diffraction densities result from the low crystallinity degree of the MSH as described in our previous work [7]. The chemical composition of four samples were further determined by ICP and EDX, and the corresponding results were summarized in Table 1 and Figure S1 (Supporting Information), respectively. One observes that all the four samples have similar chemical composition while the determined $\mathrm{Si} / \mathrm{Mg}$ ratios slightly increase with the 
same trend as the $\mathrm{Si} / \mathrm{Mg}$ feeding ratios, which are in the $\mathrm{Si} / \mathrm{Mg}$ ratio range of the reported in the literature [24].

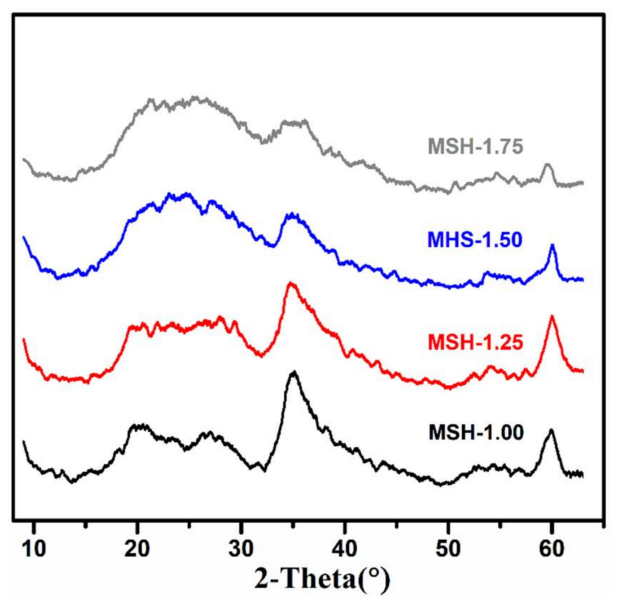

Figure 1. X-ray Diffraction (XRD) patterns of magnesium silicate hydrate samples (MSH) with different $\mathrm{Si} / \mathrm{Mg}$ feeding ratios from 1.00 to 1.75 .

Figure 2 and Figure S2 (Supporting Information) display the SEM and TEM images of four MSH samples. For all of four samples in Figure 2a and Figure S2, the morphologies from SEM are similar with the increase of $\mathrm{Si} / \mathrm{Mg}$ feeding ratio from 1.00 to 1.75, and the samples present an irregular morphology with large particle size resulting from the aggregation. Figure $2 \mathrm{~b}$ exhibits the TEM image of MSH-1.75, which are composed of lots of interlaced or aggregated nanosheets. Figure S3 (Supporting Information) further displays the particle size distributions of MSH samples tested by the laser particle size analyzer. The average particle size $\left(d_{50}\right)$ is $480,530,606$, and $615 \mathrm{~nm}$ for MSH-1.00, MSH-1.25, MSH-1.50, and MSH-1.75, respectively.

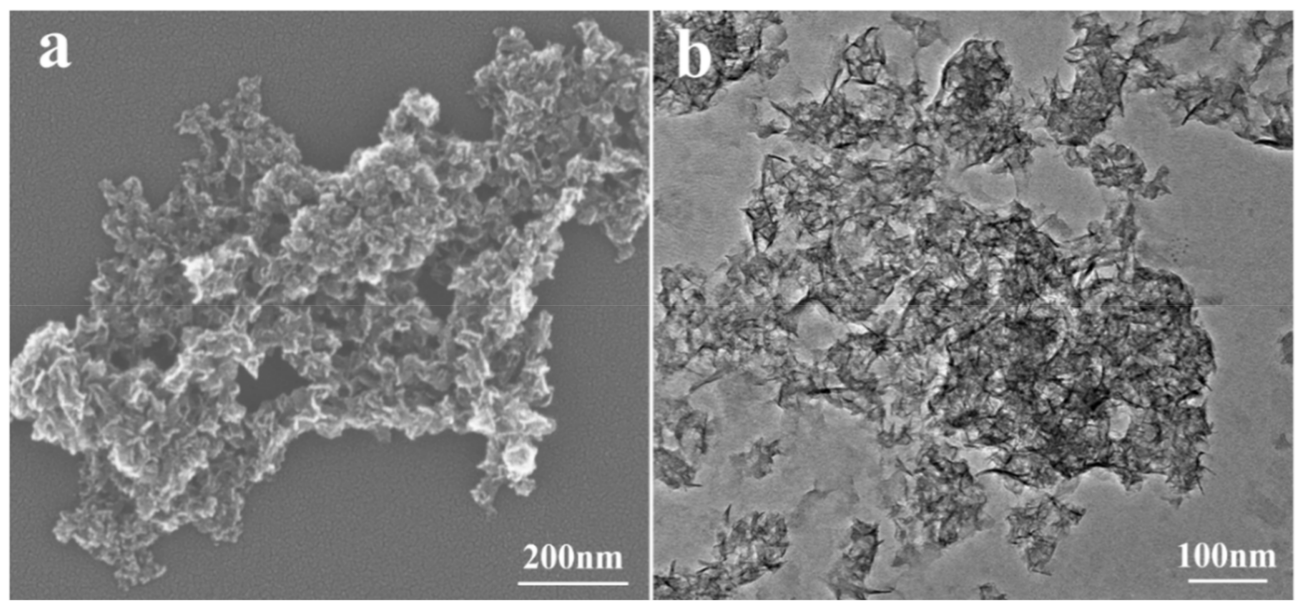

Figure 2. (a) Scanning electron microscope (SEM) and (b) Transmission electron microscope (TEM) images of MSH-1.75 sample.

Figure 3 illustrates the $\mathrm{N}_{2}$ adsorption/desorption isotherm and the pore-size distribution of four samples and all the Brunauer-Emmett-Teller (BET) data are listed in Table 1. In Figure 3a, all the samples exhibit the Type $\mathrm{H} 2$ hysteresis loop which is usually referred to pores like "ink bottle". Besides, all the samples exhibit similar pore-size distribution in Figure 3b and Figure S4 (Supporting Information) and close average pore diameter in the range of $2.28-2.56 \mathrm{~nm}$ despite the difference in the $\mathrm{Si} / \mathrm{Mg}$ feeding ratio. The surface area is decreased from $597 \mathrm{~m}^{2} \cdot \mathrm{g}^{-1}$ for MSH-1.00 to $283 \mathrm{~m}^{2} \cdot \mathrm{g}^{-1}$ for MSH-1.75. 

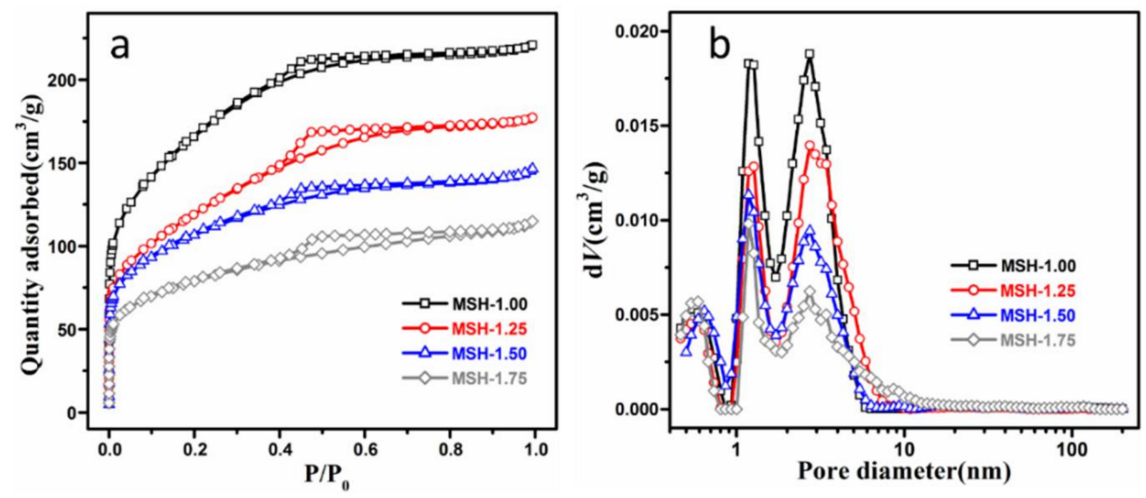

Figure 3. (a) $\mathrm{N}_{2}$ isothermal profiles of four MSH samples; (b) the pore size distribution of four samples calculated from the density functional theory (DFT).

Table 1. The inductively coupled plasma (ICP), energy-dispersive X-ray spectroscopy (EDX), and pore structure analysi results of four samples with different feeding $\mathrm{Si} / \mathrm{Mg}$ ratio.

\begin{tabular}{ccccc}
\hline Samples & $\begin{array}{c}\text { Si/Mg Molar Ratio } \\
\text { Tested by ICP }\end{array}$ & $\begin{array}{c}\text { Si/Mg Molar Ratio } \\
\text { Tested by EDX }\end{array}$ & $\begin{array}{c}\text { Surface Area } \\
\left(\mathbf{m}^{\mathbf{2}} \cdot \mathbf{g}^{\mathbf{- 1}} \mathbf{)}\right.\end{array}$ & $\begin{array}{c}\text { Average Pore } \\
\text { Diameter (nm) }\end{array}$ \\
\hline MS-1.00 & 1.06 & 1.09 & 597 & 2.28 \\
MS-1.25 & 1.20 & 1.23 & 428 & 2.56 \\
MS-1.50 & 1.41 & 1.43 & 381 & 2.37 \\
MS-1.75 & 1.66 & 1.73 & 283 & 2.51 \\
\hline
\end{tabular}

\subsection{Surface Charge and Adsorption Behavior}

Figure 4 shows the FT-IR spectra of MB powder, mixture of MSH-1.75 and MB, and MSH-1.75 before and after adsorption of MB. Before the adsorption, MSH-1.75 exhibits some typical adsorption bands for MSH, for example, the adsorption bands at 464 and $1036 \mathrm{~cm}^{-1}$ are individually attributed to the $\mathrm{Mg}-\mathrm{O}$ and $\mathrm{Si}-\mathrm{O}$ stretching vibration while the bands at 1384,1645 and $3450 \mathrm{~cm}^{-1}$ are due to the $\mathrm{O}-\mathrm{H}$ vibrations [23]. After adsorption of $\mathrm{MB}$, the characteristic absorption peak of aromatic rings at $1590 \mathrm{~cm}^{-1}$ and the $\mathrm{C}-\mathrm{N}$ stretching vibrations at 1323 and $1384 \mathrm{~cm}^{-1}$ [25] shift to 1605,1335 and $1395 \mathrm{~cm}^{-1}$, in comparison with MB. No similar change is observed for the spectrum of the mixture sample with MSH-1.75 and MB. These results confirm the existence of possible electrostatic interactions between MSH and MB after adsorption.

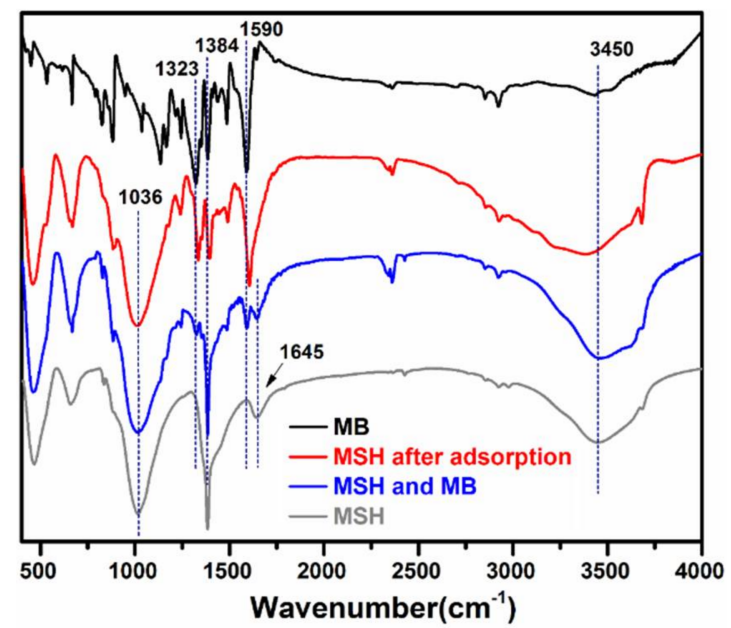

Figure 4. Fourier transform infrared spectroscopy (FT-IR) spectra of methylene blue (MB), mixture of MSH-1.75 and MB, and MSH-1.75 before and after adsorption of MB. 
Generally, surface charge plays a key role during the adsorption process, especially for the electrostatic attraction mechanism. Figure 5a shows the potentiometric titration results for four MSH samples. Firstly, the $\mathrm{pH}$ value at the zero point of charge $\left(\mathrm{pH}_{\mathrm{ZPC}}\right)$ is $7.86,7.41,7.27$ and 7.30 for MSH-1.00, $-1.25,-1.50$, and -1.75 , respectively. When the $\mathrm{pH}$ value is higher than $\mathrm{pH}_{\mathrm{ZPC}}$, all the MSH samples exhibit negative charge, resulting from the loss of the protons in the surface silanol groups [19], and furthermore the negative charge density is increased with the $\mathrm{pH}$ value. In comparison, moreover, the samples with higher $\mathrm{Si} / \mathrm{Mg}$ ratio, such as MSH-1.75 and MSH-1.50, present higher negative surface charge density than MSH-1.25 and MSH-1.00 at the same $\mathrm{pH}$ value.
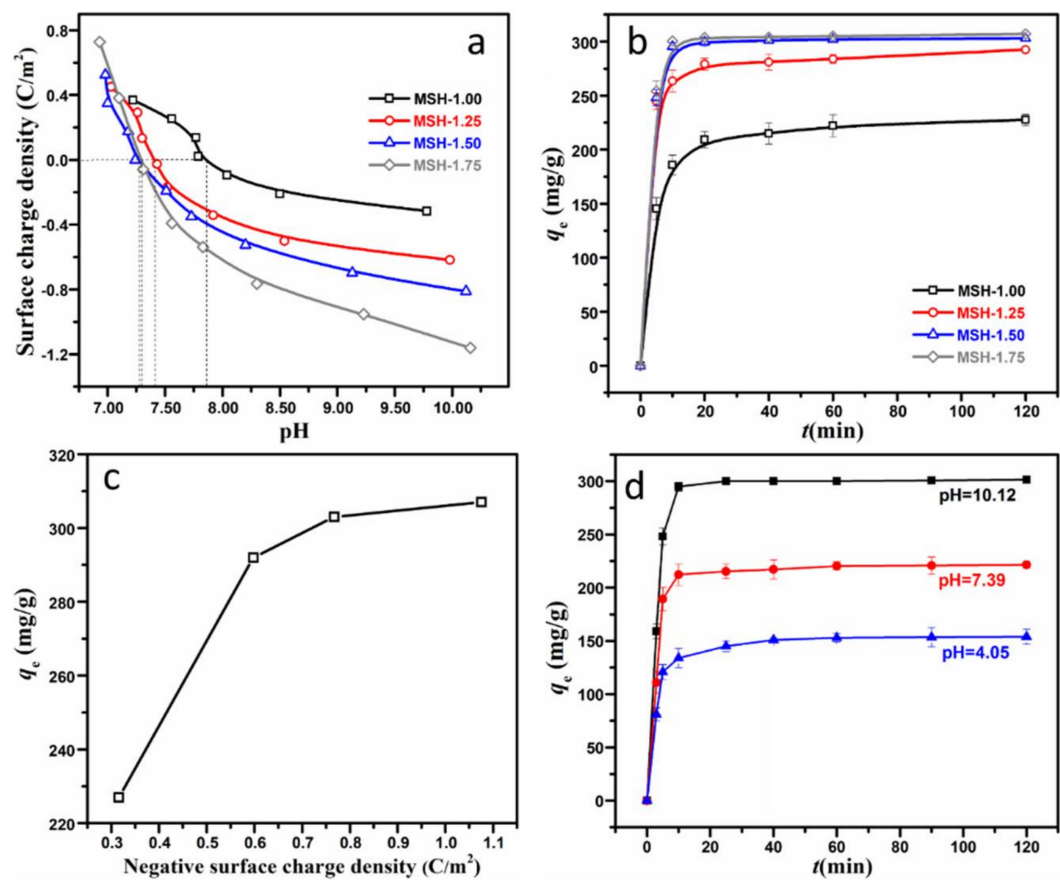

Figure 5. (a) Surface charge density of four MSH samples with different $\mathrm{Si} / \mathrm{Mg}$ feeding ratio at different $\mathrm{pH}$ values; (b) equilibrium adsorption quantity of four MSH samples for MB; (c) the relationship between equilibrium adsorption quantity and surface charge density; (d) equilibrium adsorption quantity of MSH-1.75 sample at different $\mathrm{pH}$ values.

Figure $5 \mathrm{~b}$ demonstrates the adsorption behavior of four MSH samples for MB. One observes that the adsorption of all the samples reaches the equilibrium in $120 \mathrm{~min}$. However, there is a significant difference in the equilibrium adsorption quantity among these MSH samples, for example, as for MSH-1.50 and MSH-1.75 sample, more than 90\% of the MB were removed in 10 min, and the equilibrium adsorption quantities at $120 \mathrm{~min}$ are 303 and $307 \mathrm{mg} \cdot \mathrm{g}^{-1}$ respectively, which are much higher than $227 \mathrm{mg} \cdot \mathrm{g}^{-1}$ for MSH-1.00. That is to say, the equilibrium adsorption quantity of MSH-1.75 is 0.35 times higher than that of MSH-1.00 although the surface area of MSH- $1.00\left(597 \mathrm{~m}^{2} / \mathrm{g}\right)$ is 1.1 times higher than MSH-1.75 (283 $\left.\mathrm{m}^{2} / \mathrm{g}\right)$. Figure 5c further shows that the variation trend of the equilibrium adsorption quantities is the similar with that of the surface charge densities as described in Figure 5a. Therefore, here one may conclude that the surface charge is one of key parameters concerning the adsorption behavior of MSH for the MB.

Figure $5 \mathrm{~d}$ shows the difference in the adsorption quantity of $\mathrm{MSH}-1.75$ at three different $\mathrm{pH}$ values under the same ion strength of the solution. The equilibrium adsorption quantity is $301 \mathrm{mg} \cdot \mathrm{g}^{-1} \mathrm{at}$ $\mathrm{pH}=10.12$, which is much higher than $221 \mathrm{mg} \cdot \mathrm{g}^{-1}$ at $\mathrm{pH}=7.39$ and $154 \mathrm{mg} \cdot \mathrm{g}^{-1}$ at $\mathrm{pH}=4.05$. As described in Figure 5a, the $\mathrm{pH}_{\mathrm{ZPC}}$ of MSH-1.75 is 7.30, which is lower that $\mathrm{pH}=10.12$ and higher than $\mathrm{pH}=4.05$, and very close to the $\mathrm{pH}$ value of 7.39 in this experiment. That is to say, MSH-1.75 with negative surface charge density of $-1.16 \mathrm{C} \cdot \mathrm{m}^{-2}$ exhibits ca. $36 \%$ higher adsorption capacity related to 
the same sample at the zero point of charge. The results further provide another proof for the effect of the surface charge on the adsorption capacity.

Figure 6 demonstrates the adsorption behavior of MSH-1.75 and the corresponding kinetic models for $\mathrm{MB}$ at $C_{0}=200 \mathrm{mg} \cdot \mathrm{L}^{-1}$. As shown in Figure $6 \mathrm{a}, 98.7 \%$ of the $\mathrm{MB}$ in the solution are removed by MSH-1.75 in $10 \mathrm{~min}$, and the adsorption process reaches the equilibrium in $20 \mathrm{~min}$ with the removal of 99.5\% MB. Here, two typical adsorption kinetic models (the pseudo-first-order kinetic model shown as Equation (2) [26] and the pseudo-second-order kinetic model shown as Equation (3) [27]) were used to further analyze the adsorption mechanism of MSH-1.75 for MB. Also, the corresponding results are shown in Figure $6 \mathrm{~b}$ and Figure S5 and summarized in Table 2.

$$
\begin{gathered}
\text { Pseudo-first-order kinetic : } \log \left(q_{e}-q_{t}\right)=\log \left(q_{e}\right)-\frac{k_{1}}{2.303} t \\
\text { Pseudo-second-order kinetic : } \frac{t}{q_{t}}=\frac{1}{k_{2} q_{e}^{2}}+\frac{t}{q_{e}}
\end{gathered}
$$

where $q_{e}\left(\mathrm{mg} \cdot \mathrm{g}^{-1}\right)$ and $q_{t}\left(\mathrm{mg} \cdot \mathrm{g}^{-1}\right)$ are the adsorbed quantity for MB at equilibrium and at contact time $t(\mathrm{~min})$, respectively; $k_{1}\left(\mathrm{~min}^{-1}\right)$ and $k_{2}\left(\mathrm{~g} \cdot \mathrm{mg}^{-1} \cdot \mathrm{min}^{-1}\right)$ is the rate constant for the pseudo-first-order kinetic model and the pseudo-first-order kinetic model. Through the linear relationship, the parameters such as $k_{1}, k_{2}$ and $q_{e}$ can be determined from the slope and intercept.
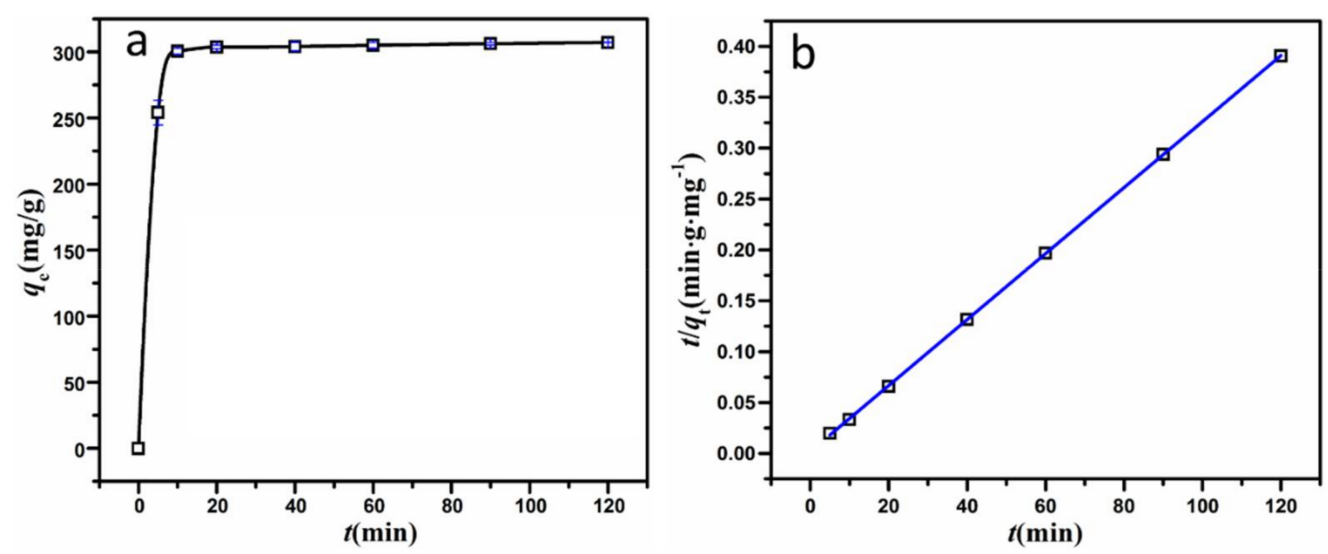

Figure 6. (a) Variation of adsorption quantity of MSH-1.75 as a function of contact time; and (b) the liner fitting of pseudo-second-order kinetics.

For MSH-1.75, the adsorption kinetic curves match the pseudo-second-order model well, with a better linear relationship in Figure $6 \mathrm{~b}$ and a relatively higher $R^{2}$ value, compared to the pseudo-first-order model in Figure S5 and Table 2. Also, the calculated $q_{\text {e.cal }}$ values from the pseudo-second-order model are very close to the experimental data $q_{\mathrm{e}, \mathrm{exp}}$.

Table 2. Pseudo-first-order and pseudo-second-order adsorption kinetic constants for MB adsorption.

\begin{tabular}{lccccccc}
\hline \multirow{2}{*}{ Sample } & $\boldsymbol{q}_{e, \mathbf{e x p}}$ & \multicolumn{3}{c}{ Pseudo-First-Order Model } & \multicolumn{3}{c}{ Pseudo-Second-Order Model } \\
\cline { 3 - 8 } & $\left(\mathbf{m g} \cdot \mathbf{g}^{-\mathbf{1}}\right)$ & $\boldsymbol{q}_{\boldsymbol{e}, \mathrm{cal}}\left(\mathbf{m g} \cdot \mathbf{g}^{-\mathbf{1}}\right)$ & $\boldsymbol{k}_{\mathbf{1}}$ & $\boldsymbol{R}^{\mathbf{2}}$ & $\boldsymbol{q}_{\boldsymbol{e}, \mathrm{cal}}\left(\mathbf{m g} \cdot \mathbf{g}^{-\mathbf{1}}\right)$ & $\boldsymbol{k}_{\mathbf{2}}$ & $\boldsymbol{R}^{\mathbf{2}}$ \\
\hline MSH-1.75 & 307 & 50.3 & 0.941 & 0.786 & 308 & 0.00552 & 0.999 \\
\hline
\end{tabular}

Figure 7 and Figure S6 show the adsorption isotherm of MSH-1.50 and MSH-1.75 for the $\mathrm{MB}$ in water after the adsorption for $120 \mathrm{~min}$, and the corresponding results are expressed in the linear form of the Freundlich adsorption isotherm (Equation (4)) and Langmuir adsorption isotherm (Equation (5)) [28,29]. 


$$
\begin{gathered}
\text { Freundlich : } \log q_{e}=\log K_{F}+\frac{1}{n} \log C_{e} \\
\text { Langmuir : } \frac{C_{e}}{q_{e}}=\frac{1}{K_{L} q_{m}}+\frac{C_{e}}{q_{m}}
\end{gathered}
$$

where $q_{e}\left(\mathrm{mg} \cdot \mathrm{g}^{-1}\right)$ and $q_{m}\left(\mathrm{mg} \cdot \mathrm{g}^{-1}\right)$ is equilibrium adsorption quantity and the maximum adsorption capacity, respectively; $C_{e}$ is the equilibrium concentration of $\mathrm{MB}$ in solution; $K_{L}$ is the equilibrium constant $\left(\mathrm{L} \cdot \mathrm{mg}^{-1}\right) ; K_{F}$ is the Freundlich isotherm constant and $n$ presents the adsorption tendency. Through the linear relationship between $C_{e} / q_{e}$ and $C_{e}, \log q_{e}$ and $\log C_{e}$, the other parameters: $q_{m}, K_{L}$, $K_{F}$ and $n$, can be calculated from the slope and intercept.
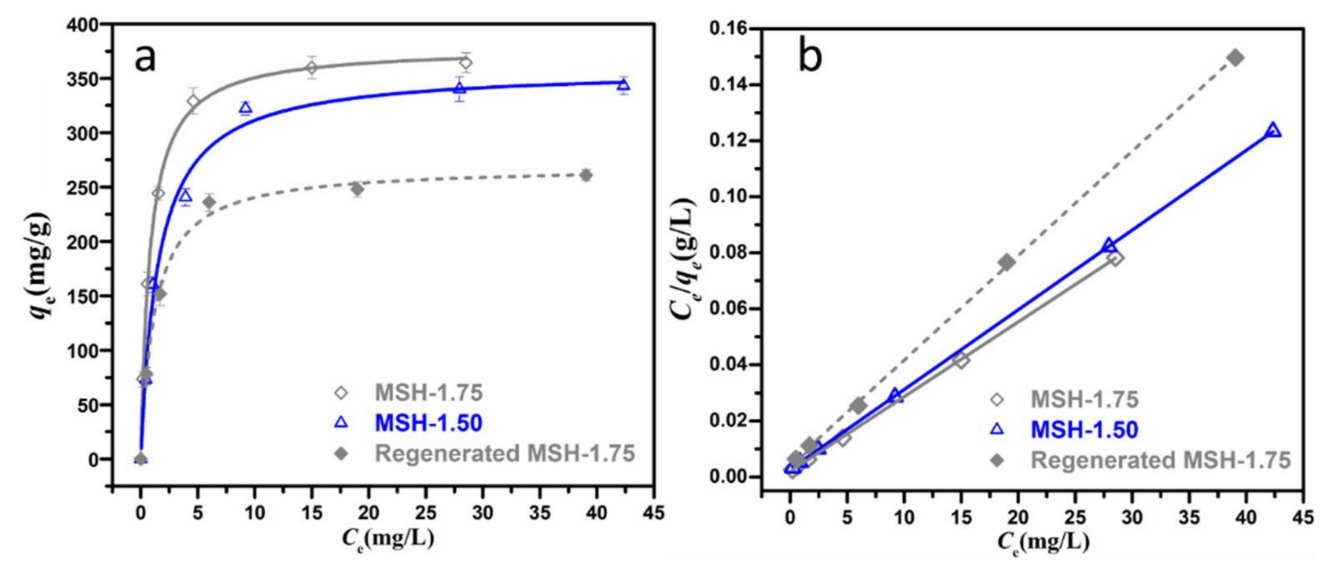

Figure 7. (a) Curve and (b) liner fitting of Langmuir isotherm for MB adsorption by MSH-1.50, MSH-1.75 and regenerated MSH-1.75 samples.

One observes that the adsorption behavior of both MSH-1.50 and MSH-1.75 samples matches the Langmuir adsorption model much better than the Freundlich isotherm with the relatively higher $R^{2}$ value as summarized in Table 3, suggesting that the adsorption of MB is much closer to the monolayer coverage on the surface of MSH sample [30]. The $q_{m}$ values of MSH-1.50 and MSH-1.75 based on the Langmuir adsorption model are 351 and $374 \mathrm{mg} \cdot \mathrm{g}^{-1}$ respectively, and the $q_{m}$ value of $374 \mathrm{mg} \cdot \mathrm{g}^{-1}$ for MSH-1.75 is the highest one among those reported in the literature as summarized in Table 4. Besides adsorption capacity, reusability is another crucial parameter for a high-performance absorbency [31]. Here, the regenerated MSH-1.75 sample exhibits a $q_{m}$ value of $268 \mathrm{mg} \cdot \mathrm{g}^{-1}$ and remains ca. $72 \%$ of $q_{m}$, suggesting promising reusability. Certainly, it still has large space to enhance reusability of the MSH by building a polymer network or porous substrate-supported composites for practical applications, although the reusability efficiency of $72 \%$ is higher than that of $60 \%$ for mesoporous magnesium silicate in ref [22]. The corresponding work is on the way. In brief, the high surface charge of the MSH sample significantly promotes the improvement of adsorption capacity for the removal of MB in aqueous solution.

Table 3. Langmuir and Freundlich isotherms parameters of MSH-1.50, MSH-1.75 and regenerated MSH-1.75 samples for MB adsorption.

\begin{tabular}{ccccccc}
\hline \multirow{2}{*}{ Sample } & \multicolumn{3}{c}{ Langmuir } & \multicolumn{3}{c}{ Freundlich } \\
\cline { 2 - 7 } & $\boldsymbol{q}_{\boldsymbol{m}}$ & $\boldsymbol{K}_{\boldsymbol{L}}$ & $\boldsymbol{R}^{\mathbf{2}}$ & $\boldsymbol{n}$ & $\boldsymbol{K}_{\boldsymbol{F}}$ & $\boldsymbol{R}^{\mathbf{2}}$ \\
\hline MSH-1.50 & 351 & 1.04 & 0.999 & 3.59 & 146 & 0.834 \\
MSH-1.75 & 374 & 1.34 & 0.999 & 3.31 & 166 & 0.820 \\
Regenerated MSH-1.75 & 268 & 0.84 & 0.999 & - & - & - \\
\hline
\end{tabular}


Table 4. Summaries of adsorption capacity of various adsorbents for MB under a certain condition.

\begin{tabular}{cccccc}
\hline Adsorbents & $\begin{array}{c}\text { Equilibrium } \\
\text { Time }\end{array}$ & $\begin{array}{c}\mathbf{p H} \\
\text { Value }\end{array}$ & $\begin{array}{c}\text { Surface Area } \\
\left(\mathbf{m}^{\mathbf{2}} \cdot \mathbf{g}^{-\mathbf{1}}\right)\end{array}$ & $\begin{array}{c}\text { Adsorption } \\
\text { Capacity } \mathbf{( m g} \cdot \mathbf{g}^{-\mathbf{1}} \mathbf{)}\end{array}$ & Ref. \\
\hline MgSi hollow spheres & $30 \mathrm{~min}$ & - & 521 & 207 & {$[32]$} \\
Florisil & $4 \mathrm{~h}$ & - & 250 & 149.3 & {$[17]$} \\
t-yolk-shell magnetic MgSi & $15 \mathrm{~h}$ & - & 293 & 188 & {$[11]$} \\
MgSi nanotubes & - & - & 649 & 276 & {$[4]$} \\
Diatomite & $48 \mathrm{~h}$ & 11 & 27.8 & 198 & {$[19]$} \\
Activated carbon & $90 \mathrm{~min}$ & - & 984 & 68.72 & {$[33]$} \\
Graphene-c-MWCNT hybrid aerogel & - & - & 435 & 190.0 & {$[34]$} \\
Copper silicate hollow nanotubes & - & - & 518 & 173 & {$[35]$} \\
Modified montmorillonite clays & - & - & - & 71 & {$[21]$} \\
GO-CS hydrogels & $58 \mathrm{~h}$ & 6.5 & - & 350 & {$[36]$} \\
MSH-1.75 & $2 \mathrm{~h}$ & 10.1 & 283 & 374 & this work \\
\hline
\end{tabular}

\section{Conclusions}

In this work, we successfully fabricated magnesium silicate hydrate (MSH) adsorbents with different surface charge by adjusting the $\mathrm{Si} / \mathrm{Mg}$ feeding ratios, and examined the relationship between surface charge density and adsorption behavior for methylene blue (MB) in aqueous solution. The $\mathrm{Si} / \mathrm{Mg}$ feeding ratios significantly modify the surface charge density of $\mathrm{MSH}$, and then influence the adsorption capacity for MB in aqueous solution. Among the investigated four samples, MSH-1.75 has the highest negative surface charge density of $-1.16 \mathrm{C} \cdot \mathrm{m}^{-2}$ and exhibits ca. $36 \%$ higher adsorption capacity related to the same sample at the zero point of charge. With the largest adsorption capacity of $374 \mathrm{mg} \cdot \mathrm{g}^{-1}$ calculated from the Langmuir isotherm, furthermore, the MSH materials show good regeneration ability with ca. $72 \%$ of reusability efficiency. Therefore, this is an available route to improve the removal capacity of magnesium silicate hydrate for cationic dyes by increasing the corresponding negative surface charge density. Furthermore, magnesium silicate hydrate is one kind of promising material for removing dye pollution from wastewater.

Supplementary Materials: The following are available online at http:/ /www.mdpi.com/2079-4991/8/5/271/s1.

Author Contributions: Yongjun Feng and Yingying Zhao conceived and designed the experiments; Renyao Huang, Li He, Tao Zhang performed the experiments; Renyao Huang, Li He, Tao Zhang analyzed the data; Yongjun Feng, Dianqing Li, Pinggui Tang, Yingying Zhao interpreted the data; Yongjun Feng contributed reagents/materials/analysis tools; Renyao Huang, Yongjun Feng and Yingying Zhao wrote the paper.

Acknowledgments: This work is supported by the National Key R\&D Program of China (No. 2016YFB0301600), the Natural Science Foundation of China, the Fundamental Research Funds for the Central Universities (JD1716), and Program for Changjiang Scholars and Innovative Research Team in University (No. IRT1205).

Conflicts of Interest: The authors declare no conflict of interest.

\section{References}

1. Rane, N.R.; Chandanshive, V.V.; Khandare, R.V.; Gholave, A.R.; Yadav, S.R.; Govindwar, S.P. Green Remediation of Textile Dyes Containing Wastewater by Ipomoea hederifolia L. RSC Adv. 2014, 4, 36623-36632. [CrossRef]

2. Extremera, R.; Pavlovic, I.; Pérez, M.R.; Barriga, C. Removal of Acid Orange 10 by Calcined Mg/Al Layered Double Hydroxides from Water and Recovery of the Adsorbed Dye. Chem. Eng. J. 2012, 213, 392-400. [CrossRef]

3. Razali, M.; Kim, J.F.; Attfield, M.; Budd, P.M.; Drioli, E.; Lee, Y.M.; Szekely, G. Sustainable Wastewater Treatment and Recycling in Membrane Manufacturing. Green Chem. 2015, 17, 5196-5205. [CrossRef]

4. Qu, J.; Li, W.; Cao, C.-Y.; Yin, X.-J.; Zhao, L.; Bai, J.; Qin, Z.; Song, W.-G. Metal Silicate Nanotubes with Nanostructured Walls as Superb Adsorbents for Uranyl Ions and Lead Ions in Water. J. Mater. Chem. 2012, 22, 17222-17226. [CrossRef]

5. Özcan, A.; Öncü, E.M.; Özcan, A.S. Kinetics, Isotherm and Thermodynamic Studies of Adsorption of Acid Blue 193 from Aqueous Solutions onto Natural Sepiolite. Colloids Surf. A 2006, 277, 90-97. [CrossRef] 
6. Lu, Q.; Li, Q.; Zhang, J.; Li, J.; Lu, J. Facile Mesoporous Template-Assisted Hydrothermal Synthesis of Ordered Mesoporous Magnesium Silicate as an Efficient Adsorbent. Appl. Surf. Sci. 2016, 360, 889-895. [CrossRef]

7. Huang, R.; Wu, M.; Zhang, T.; Li, D.; Tang, P.; Feng, Y. Template-Free Synthesis of Large-Pore-Size Porous Magnesium Silicate Hierarchical Nanostructures for High-Efficiency Removal of Heavy Metal Ions. ACS Sustain. Chem. Eng. 2017, 5, 2774-2780. [CrossRef]

8. Narasimharao, K.; Ali, T.T.; Bawaked, S.; Basahel, S. Effect of Si Precursor on Structural and Catalytic Properties of Nanosize Magnesium Silicates. Appl. Catal. A Gen. 2014, 488, 208-218. [CrossRef]

9. Gui, C.X.; Wang, Q.Q.; Hao, S.M.; Qu, J.; Huang, P.P.; Cao, C.Y.; Song, W.G.; Yu, Z.Z. Sandwichlike Magnesium Silicate/Reduced Graphene Oxide Nanocomposite for Enhanced $\mathrm{Pb}^{2+}$ and Methylene Blue Adsorption. ACS Appl. Mater. Interfaces 2014, 6, 14653-14659. [CrossRef] [PubMed]

10. Cao, C.Y.; Wei, F.; Qu, J.; Song, W.G. Programmed Synthesis of Magnetic Magnesium Silicate Nanotubes with High Adsorption Capacities for Lead and Cadmium Ions. Chem. Eur. J. 2013, 19, 1558-1562. [CrossRef] [PubMed]

11. Zheng, J.; Cheng, C.; Yan, R.-W.; Fang, W.-J.; Chen, C.; Huai, H.-X.; Wang, C.-C. Synthesis of Yolk-Shell Magnetic Magnesium Silicate with Tunable Yolk Morphology for Removal of Methylene Blue in Water. J. Alloys Compd. 2014, 596, 5-9. [CrossRef]

12. Yari, S.; Abbasizadeh, S.; Mousavi, S.E.; Moghaddam, M.S.; Moghaddam, A.Z. Adsorption of Pb(II) and $\mathrm{Cu}(\mathrm{II})$ Ions from Aqueous Solution by an Electrospun $\mathrm{CeO}_{2}$ Nanofiber Adsorbent Functionalized with Mercapto Groups. Process Saf. Environ. 2015, 94, 159-171. [CrossRef]

13. Tripathi, S.; Bose, R.; Roy, A.; Nair, S.; Ravishankar, N. Synthesis of Hollow Nanotubes of $\mathrm{Zn}_{2} \mathrm{SiO}_{4}$ or $\mathrm{SiO}_{2}$ : Mechanistic Understanding and Uranium Adsorption Behavior. ACS Appl. Mater. Interfaces 2015, 7, 26430-26436. [CrossRef] [PubMed]

14. Homaeigohar, S.; Zillohu, A.U.; Abdelaziz, R.; Hedayati, M.K.; Elbahri, M. A Novel Nanohybrid Nanofibrous Adsorbent for Water Purification from Dye Pollutants. Materials 2016, 9, 848. [CrossRef] [PubMed]

15. Janaki, V.; Oh, B.-T.; Shanthi, K.; Lee, K.-J.; Ramasamy, A.K.; Kamala-Kannan, S. Polyaniline/Chitosan Composite: An Eco-Friendly Polymer for Enhanced Removal of Dyes from Aqueous Solution. Synth. Met. 2012, 162, 974-980. [CrossRef]

16. Dogan, M.; Alkan, M.; Turkyilmaz, A.; Ozdemir, Y. Kinetics and Mechanism of Removal of Methylene Blue by Adsorption onto Perlite. J. Hazard. Mater. 2004, 109, 141-148. [PubMed]

17. Ferrero, F. Adsorption of Methylene Blue on Magnesium Silicate: Kinetics, Equilibria and Comparison with Other Adsorbents. J. Environ. Sci. 2010, 22, 467-473. [CrossRef]

18. Ravikovitch, P.I.; Haller, G.L.; Neimark, A.V. Density Functional Theory Model for Calculating Pore Size Distributions: Pore Structure of Nanoporous Catalysts. Adv. Colloid Interface Sci. 1998, 76-77, 203-226. [CrossRef]

19. Al-Ghouti, M.A.; Khraisheh, M.A.M.; Allen, S.J.; Ahmad, M.N. The Removal of Dyes from Textile Wastewater: A Study of the Physical Characteristics and Adsorption Mechanisms of Diatomaceous Earth. J. Environ. Manag. 2003, 69, 229-238. [CrossRef]

20. Wang, W.; Tian, G.; Zhang, Z.; Wang, A. A Simple Hydrothermal Approach to Modify Palygorskite for High-Efficient Adsorption of Methylene Blue and Cu(II) Ions. Chem. Eng. J. 2015, 265, 228-238. [CrossRef]

21. Cottet, L.; Almeida, C.A.P.; Naidek, N.; Viante, M.F.; Lopes, M.C.; Debacher, N.A. Adsorption Characteristics of Montmorillonite Clay Modified with Iron Oxide with Respect to Methylene Blue in Aqueous Media. Appl. Clay Sci. 2014, 95, 25-31. [CrossRef]

22. Zhang, J.; Dang, L.; Zhang, M.; Lu, Q.; Zhao, S. Characterization of Mesoporous Magnesium Silicate with Hierarchical Structure and Its Adsorption Performance for Dye and Lead Ion. Surf. Interfaces 2017, 8, 112-118. [CrossRef]

23. Brew, D.R.M.; Glasser, F.P. Synthesis and Characterisation of Magnesium Silicate Hydrate Gels. Cem. Concr. Res. 2005, 35, 85-98. [CrossRef]

24. Bernard, E.; Lothenbach, B.; Rentsch, D.; Pochard, I.; Dauzères, A. Formation of Magnesium Silicate Hydrates (M-S-H). Phys. Chem. Earth 2017, 99, 142-157. [CrossRef]

25. Wu, Z.; Zhong, H.; Yuan, X.; Wang, H.; Wang, L.; Chen, X.; Zeng, G.; Wu, Y. Adsorptive Removal of Methylene Blue by Rhamnolipid-Functionalized Graphene Oxide from Wastewater. Water Res. 2014, 67, 330-344. [CrossRef] [PubMed] 
26. Zhang, M.; Song, L.; Jiang, H.; Li, S.; Shao, Y.; Yang, J.; Li, J. Biomass Based Hydrogel as An Adsorbent for the Fast Removal of Heavy Metal Ions from Aqueous Solutions. J. Mater. Chem. A 2017, 5, 3434-3446. [CrossRef]

27. Yu, R.; Shi, Y.; Yang, D.; Liu, Y.; Qu, J.; Yu, Z.Z. Graphene Oxide/Chitosan Aerogel Microspheres with Honeycomb-Cobweb and Radially Oriented Microchannel Structures for Broad-Spectrum and Rapid Adsorption of Water Contaminants. ACS Appl. Mater. Interfaces 2017, 9, 21809-21819. [CrossRef] [PubMed]

28. Chen, Y.; He, M.; Wang, C.; Wei, Y. A Novel Polyvinyltetrazole-Grafted Resin with High Capacity for Adsorption of $\mathrm{Pb}(\mathrm{II}), \mathrm{Cu}(\mathrm{II})$ and $\mathrm{Cr}(\mathrm{III})$ Ions from Aqueous Solutions. J. Mater. Chem. A 2014, 2, 10444-10453. [CrossRef]

29. Ghaemi, A.; Torab-Mostaedi, M.; Ghannadi-Maragheh, M. Characterizations of Strontium(II) and Barium(II) Adsorption from Aqueous Solutions Using Dolomite Powder. J. Hazard. Mater. 2011, 190, 916-921. [CrossRef] [PubMed]

30. Pan, Y.; Liu, Z.; Wang, W.; Peng, C.; Shi, K.; Ji, X. Highly Efficient Macroporous Adsorbents for Toxic Metal Ions in Water Systems Based on Polyvinyl Alcohol-Formaldehyde Sponges. J. Mater. Chem. A 2016, 4, 2537-2549. [CrossRef]

31. Kupai, J.; Razali, M.; Buyuktiryaki, S.; Kecili, R.; Szekely, G. Long-Term Stability and Reusability of Molecularly Imprinted Polymers. Polym. Chem. 2017, 8, 666-673. [CrossRef] [PubMed]

32. Wang, Y.; Wang, G.; Wang, H.; Liang, C.; Cai, W.; Zhang, L. Chemical-Template Synthesis of Micro/Nanoscale Magnesium Silicate Hollow Spheres for Waste-Water Treatment. Chem. Eur. J. 2010, 16, 3497-3503. [CrossRef] [PubMed]

33. Kumar, P.S.; Ramalingam, S.; Sathishkumar, K. Removal of Methylene Blue Dye from Aqueous Solution by Activated Carbon Prepared from Cashew Nut Shell as a New Low-Cost Adsorbent. Korean J. Chem. Eng. 2010, 28, 149-155. [CrossRef]

34. Sui, Z.; Meng, Q.; Zhang, X.; Ma, R.; Cao, B. Green Synthesis of Carbon Nanotube-Graphene Hybrid Aerogels and Their Use as Versatile Agents for Water Purification. J. Mater. Chem. 2012, 22, 8767-8771. [CrossRef]

35. Zhang, M.; Wang, B.; Zhang, Y.; Li, W.; Gan, W.; Xu, J. Facile Synthesis of Magnetic Hierarchical Copper Silicate Hollow Nanotubes for Efficient Adsorption and Removal of Hemoglobin. Dalton Trans. 2016, 45, 922-927. [CrossRef] [PubMed]

36. Chen, Y.; Chen, L.; Bai, H.; Li, L. Graphene Oxide-Chitosan Composite Hydrogels as Broad-Spectrum Adsorbents for Water Purification. J. Mater. Chem. A 2013, 1, 1992-2001. [CrossRef] 